\title{
What's the Half-Life of the Economic Vote? (About a Year and a Half) ${ }^{*}$
}

\author{
Jack Bailey $^{\dagger}$ \\ This version: May 01, 2021
}

\begin{abstract}
Economic voting research assumes that voters focus their attention on the recent past. Yet testing this assumption is difficult and previous research remains inconclusive. To estimate voters' economic time frames, I specify a new model that relies on insights from the physical sciences. I show that voter myopia is real and that the economic vote is strongest when economic time frames are shortest. After around a year and a half, its effect falls by half. After seven years, it becomes practically equivalent to zero. This suggests that voters are less short-sighted than some past research suggests. Yet, there is still some cause for concern: voters' economic time frames remain short enough that governments may receive undeserved leeway for mistakes they make early in their tenure.
\end{abstract}

${ }^{*}$ This article benefitted from much useful feedback. Thank you to Matthew Barnfield, Ed Fieldhouse, Jon Mellon, Marta Cantijoch, and members of the European University Institute's Political Behaviour Colloquium, the University of Manchester's Democracy and Elections cluster, and those present at the 2021 Midwest Political Science Association Conference for their time and their wisdom. Thank you finally to Richard McElreath who was kind enough to share the code necessary to make the nice equation labels that I use here.

${ }^{\dagger}$ Research Associate, Department of Politics, The University of Manchester, UK. If you have any comments or questions, feel free to contact me either by email (jack.bailey@manchester.ac.uk) or on Twitter (@PoliSciJack). 


\section{Introduction}

In 1992, MacKuen, Erikson, and Stimson argued that economic voting research had moved "little beyond introspection in understanding the processes by which citizens come to perceive economic movement" (MacKuen, Erikson, and Stimson 1992, 597). Three decades later, and we remain none the wiser. As in the early-1990s, economic voting scholars now believe that voters are both retrospective and myopic. They vote based on the difference between present and past conditions, though can only remember so far back in time. Yet-again as in the early-1990seconomic voting scholars still do not know just how retrospective or how myopic voters really are.

This matters because myopic voters are open to abuse. Two issues are most important. First, that voter myopia allows governments to do what they like early in their term, safe in the knowledge that voters will have forgotten by the next election. Clearly, this would be bad news for democratic accountability: it would permit governments to pursue their own priorities and not those of their voters. Second, that myopic voters might not vote for the best economic managers but, instead, the best economic manipulators. When they control the levers of the state, parties can and do use their power to shape voters' preferences in their own favour (Dunleavy and Ward 1981). Voter myopia lets them do so strategically. They might, for example, pull out all the stops to make sure that the economy is booming come election time. And if this has negative consequences down the line, then so be it: voters will probably not remember anyway. As a result, myopic voters might expect the party to ensure strong economic growth, but be stuck with worse outcomes than if they had voted for someone else.

Given these gaps in our understanding, most economic voting research makes do with as-hoc assumptions. But, as different scholars make different assumptions, the time frames that they expect voters to use often vary from one project to the next. Consider the following examples. Some economic voting scholars assume that voters respond to economic change only in the year before an election (Bloom and Price 1975; Kramer 1971). Some, instead, that voters respond to the difference between the average economic growth in the first three quarters of the election year and the average of the entire previous year (Lewis-Beck, Nadeau, and Foucault 2013). But 
this is not all. Further others assume that voters respond either to simple year-on-year (Palmer and Whitten 2011; Clarke, Stewart, and Zuk 1986; Goodhart and Bhansali 1970), quarter-onquarter (Lanoue 1987), or even month-on-month (Matthew J. Lebo and Cassino 2007) changes in the state of the economy.

My intention in this paper is to put these assumptions to rest. I test voter myopia by estimating how voters' support for the incumbent party responds to economic change over different periods of time. To do so, I rely on insights from the physical sciences: I borrow the concept of a "half-life" from pharmacology, biology, and nuclear physics. Like an hour, a minute, or a second, a half-life is a unit of time. But, unlike these familiar measures, it does not reflect a fixed interval. Rather, it reflects the average amount of time that it takes for some quantity to decay to half of its initial value. This is useful when we want to estimate how long it takes for radioactive decay to reduce the mass of a block of uranium by half or for the body's various physiological processes to remove some drug from a patient's bloodstream. That is, to estimate the half-life of a substance. Here, instead, I use individual-level data from the Comparative Study of Electoral Systems Integrated Module Dataset (Quinlan et al. 2018) and aggregate-level measures GDP data from the Organisation for Economic Co-operation and Development (OECD 2021) to estimate the half-life of a parameter: the economic vote itself.

I show that voters are myopic: they vote based on economic change in the recent past. As the time between the past and the present increases, the economic vote begins to fade away. After around a year and a half, it reaches its half-life. After around seven years, it decays to such an extent that it is all but equal to zero. As such, we should not expect voters to judge their governments based on the cumulative economic change across their time in office, even if that is what voters say they intend to do (Healy and Lenz 2014; Hibbs 2006). Instead, we should expect economic growth over the final few years of a government's term to affect the choices that voters make, with diminishing returns.

My results have two main implications. First, they suggest that voters are not quite as shortsighted as some past research would have us believe. They vote based not only on economic change at the time of the election, but also on economic change further into the past too. Second, 
and nevertheless, voters myopia remains strong enough to provide governments with an effective "get out of jail free" card. As I show, economic voting effects decay rapidly. Thus, governments may stand to benefit from undeserved leeway for decisions that they make early in their tenure.

\section{How Retrospective are Retrospective Voters?}

It seems reasonable to expect voters to forget all sorts of details that political scientists might think of as important. After all, voters often show very little interest in politics (Zaller 1992; Campbell et al. 1960), no one has a perfect memory, and to forget appears to be a fundamental aspect of how human beings process information (Ariely and Carmon 2000).

Presumably, this is even more true for complex topics like the economy. Not only are there no end of figures to remember, these figures also change value, are subject to revision, and relate to each other in all manner of different ways (Stevenson and Duch 2013). To make matters worse, most people receive little to no formal education in economics. Thus, they must rely on folk theory and the information that they glean from the news and their day-to-day lives to make sense of what is going on. No wonder then that they seem not to know how the economy is really doing (Paldam and Nannestad 2000), or at least not without a little help (Ansolabehere, Meredith, and Snowberg 2013).

Consequently, it would seem very unusual to expect voters to retain far-reaching and detailed memories of the economy's every ebb and flow. But, though the economic voting literature now includes more than 600 articles and books (Lewis-Beck and Costa Lobo 2017), research on voter myopia remains limited. Most economic voting scholars simply assume it away. The few pieces of research that do engage with the problem tend to do so in one of two ways: a voter-centric approach that relies on individual-level data and experimental methods or an electorate-centric approach that relies on aggregate-level time series data. Each approach has its own strengths and weaknesses, and comparing findings from one to the other can be difficult. Still, both tend to come to the same conclusion: that voters' economic time frames are short. Yet how short they really are remains an open question. 


\section{Voter-Centric Research}

Stiers, Dassonneville, and Lewis-Beck (2019) provide a useful starting point as they make perhaps the most forceful argument that voters are "attentive to the government's performance in the long run as well as the short” $(2019,647)$. Their argument hinges on voter psychology. They claim that proponents of voter myopia make the implicit assumption that voters engage in memory-based information processing. Here, voters store information (e.g. economic conditions) in memory until such time as it is needed (e.g. to form an economic perception). As they note, storing such information over a government's entire term is burdensome and perhaps beyond what we might expect of the average voter. Instead, they contend that voters rely on online processing and update their beliefs as though maintaining a running tally ${ }^{1}$.

My own view is that it is unclear why information processing style should affect voter myopia. I make this point because retrospective voting under either memory-based or online processing requires exactly the same amount of information. A running tally is certainly more efficient than cataloguing events if one's intention is to maintain a belief about the present state of the economy. But that is not the task at hand for retrospective voters. As Fiorina (1981) argues, when deciding how to vote "citizens need only calculate the changes in their own welfare" (p.5, emphasis own). Thus, voters must ask themselves the same question that Ronald Reagan posed during the 1980 US Presidential election campaign, "Are you better off than you were four years ago?" Note that this requires not one but two pieces of information: present and past conditions. Thus, voters must retain either two specific memories (if we assume memory-based processing) or two running tallies (if we assume online processing). As a result, both appear equally demanding.

Stiers, Dassonneville, and Lewis-Beck (2019) test their argument by using panel data from the Netherlands and the US to model incumbent voting as a function of voters' current and past

\footnotetext{
${ }^{1}$ Note that Green, Palmquist, and Schickler (2002) argue in favour of a similar model, according to which voters update their opinions as if engaging in Bayesian updating. That is, they have some prior belief, encounter some new information, which they then use to update their prior so as to arrive at some new posterior belief. In making their argument, Green, Palmquist, and Schickler (2002) touch upon how informative voters' past beliefs are of their present ones. Though similar, this is not the same issue that I contend with in this article. Green, Palmquist, and Schickler (2002) look forward and ask how voters use new information to update their opinions. Voter myopia, instead, looks backwards and asks, given that learning has already occurred, for how long does old information continue to influence current behaviours.
} 
satisfaction with the government in one model and with the economy in another. But there is now much evidence that these attitudinal items come with serious health warnings. For instance, we have long known that all manner of personal attributes affect how voters respond to these items (Conover, Feldman, and Knight 1987). But new evidence also suggests that they also exhibit trait-like stability (Kiley and Vaisey 2020). As such, we cannot rule out the possibility that both current and past items really tap into some stable latent trait and not distinct and independent evaluations of real material conditions. It is for these reasons that some have claimed that perceptual items are "so badly and unpredictably biased as to be essentially unrelated to the underlying individual-level behavioral relationship we are trying to estimate” [Kramer (1983); p.93]. Accordingly, while Stiers, Dassonneville, and Lewis-Beck (2019) provide a useful starting point, it is not clear that they provide the final word.

The remaining voter-centric work on voter myopia relies on experimental methods and not observational data. Huber, Hill, and Lenz (2012), for example, note that psychological evidence suggests that people use a heuristic called the "peak-end rule" to keep track of their utility over time: they rate an experience based on either how it ended or how it was at its most intense (Ariely and Carmon 2000). They specify an experimental game to test this in a retrospective voting setting and vary when they make their subjects aware of the upcoming "election." They find that those subjects who became aware later tended also to overweight incumbent performance closer to the event. This, they argue, suggests that voter myopia arises due to fundamental limits in people's ability to make retrospective judgements and not only the complexity that they face in the real world.

Healy and Lenz (2014) conduct a similar study, again drawing on the peak-end rule. Their design is interesting as they allow their subjects to explain how they intend to weight the economy in each year of the incumbent's term before they conduct their experiment. Consistent with Hibbs (2006), their subjects say that they intend to judge the incumbent party based on the cumulative economic change over its entire term in office. But, just like Huber, Hill, and Lenz (2012), Healy and Lenz (2014) show that their subjects do not. Rather, they "substitute the end for the whole" and focus their attention on election year performance. 


\section{Electorate-Centric Research}

Most electorate-centric research follows the precedent set by Hibbs (1987) and focusses not only on how myopic voters are but also the functional form that their myopia takes ${ }^{2}$. Hibbs' approach is as follows. First, he assumes that voters' memories of the economy decay at some known exponential rate. Next, he takes past estimates of year-on-year real income growth, weights them according to his exponential function, and then uses them to predict incumbent vote share at past US presidential elections. This, he claims, shows that voters are myopic. Achen and Bartels (2016) come to a similar conclusion using Hibbs' approach but with a longer time series. But they also show that a more limited model which assumes that voters respond only to economic growth in the two quarters before an election performs just as well.

Wlezien (2015) argues that these approaches are overly-conservative and that the extent to which we consider the electorate to be myopic depends on the functional form that we assume their myopia to take. Rather than use an exponential weighting function like Hibbs, he uses a logistic one instead. Due to its shape, the logistic function is less conservative and allows voters some time to reflect on the recent past. Wlezien's results imply that voters are myopic, though less so than often thought: they do not respond to economic growth at the very start of the incumbent's term, but they do respond to it over at least the past few years.

These approaches requires two assumptions. The first is the assumption that voter myopia takes some known form, whether exponential or otherwise. Of course, to do so reliably requires prior knowledge of how myopic voters are. But if this knowledge were available then there would be no need to conduct the research at all. The second is that these models assume that voters in the present should care about economic growth over the past year, but also, for example, between one year ago and two years ago or between 6 months ago and 18 months ago. While there might be arguments in favour of such a lag structure, it is not consistent with the retrospective voting theory that underpins most economic voting research. If they engage in retrospective voting,

\footnotetext{
${ }^{2}$ Note that while some discuss "memory" with regards to fractionally integrated aggregate-level data (see, for example, Matthew J. Lebo, Walker, and D. Clarke 2000; Matthew J. Lebo and Clarke 2000), this research concerns the degree of memory across a time series of one single indicator (e.g. the consumer confidence index) and not the topic of discussion here: the decay in the effect of one indicator (GDP) on another (voting behaviour)
} 
voters should not care about lagged year-on-year economic growth, but instead the difference between economic conditions now and at some point in the past (Fiorina 1981).

\section{Towards a Hybrid Approach}

I have hoped to show that much uncertainty remains in our understanding of voter myopia. Ultimately, this is because estimating voters' retrospective economic time frames is difficult. Voter-centric approaches have had to deal with items that suffer from known biases (Kiley and Vaisey 2020; Conover, Feldman, and Knight 1987; Kramer 1983) and experimental methods that may not generalise outside of the survey context (Barabas and Jerit 2010). Likewise, electorate-centric approaches have had to make ad-hoc assumptions about how voters forget and have often suffered with problems of ecological inference (Stewart and Clarke 2017).

The most sensible way forward would seem to be to combine the strengths of each approach. To avoid problems of ecological inference, we can draw on individual-level voting intention data. And to avoid problems of systematic perceptual bias, we can draw on aggregate-level economic statistics. Such a hybrid approach is rare in the economic voting literature (though see Reidy, Suiter, and Breen 2017). The reason is that it is hard to find individual-level data sets that one can match to aggregate-level economic data to arrive at a sufficient amount of aggregate-level economic variation. But where this data exists, it offers the possibility of estimating voters' retrospective time frames in a way that avoids many prevailing difficulties.

\section{Data}

My individual-level voting intention data come from the Comparative Study of Electoral Systems Integrated Module Dataset (Quinlan et al. 2018). The CSES comprise a series of modules appended to many national election studies. These cover elections from the mid-1990s to the present day across a range of countries, themselves nested within a range of continents.

I endeavour to include as much of the data as possible in my analysis though limit my cases selection in two particular ways. First, I omit any countries that the V-Dem Institute deems not to be democratic. In particular, I remove any elections that occurred where a country received 
an electoral democracy score from V-Dem of less than 0.5 (Coppedge et al. 2020). Second, I include only those countries for which I can obtain comparable economic data. As I discuss below, I limit my focus to those countries either in the OECD or for which there are economic statistics available in the OECD's Quarterly National Accounts (2021).

After removing any problem cases, the resulting data include information on 151,822 voters at 116 elections in 34 countries. The first election in my data took place on 2 March 1996 in Australia and the most recent on 19 October 2015 in Canada. What's more, cases include the usual suspects in North America and Europe, but also countries in Oceania (Australia, New Zealand), Asia (South Korea, Japan), Latin America (Brazil, Chile), and the Middle East (Israel). As such, there is good reason to believe that my results should be widely generalisable ${ }^{3}$.

My aggregate-level economic data come from the OECD’s Quarterly National Accounts (OECD 2021). The economic voting literature most often uses GDP as its indicator of choice. Indeed, some even call it "the most general objective measure of economic welfare" (Kayser and Wlezien 2011, 376). I follow suit. Fortunately, the OECD obliges its members to provide quarterly economic data in a range of comparable formats. For this study, I use their time series of quarterly, expenditure-based, seasonally-adjusted GDP in national currency, and at chained volume measure to account for the effect of inflation.

I match each case in the CSES to the most recent quarterly estimate of national GDP on the date of the election, plus all other quarters between the date of the most recent election and the date of the previous election. I then compute GDP growth in percentage terms between GDP at the date of the election and all previous quarters. As term limits vary from one country to the next, so too did the number of quarters. The number of quarters ranged from a low of 1 (Czech Republic, 31 May 1996) to a high of 28 (France, 21 April 2002). As some elections took place up to 7 years apart, my estimates of GDP growth between the time of the election and all previous quarters showed much variation. In total, the indicator included 1,612 different values ranging from a low of $-23.1 \%$ to a high of $43.3 \%$.

\footnotetext{
${ }^{3}$ Unfortunately, my data include no cases from Africa. This is in part due to a lack of African national election studies in the CSES data and the fact that no African nations are part of the OECD
} 


\section{Methods}

Specifying a model that estimates both the economic vote and voter myopia requires some flexibility. As this is difficult using Frequentist methods, I use a Bayesian approach instead. The resulting model is quite complex, so it is prudent to start with a simpler model and then build up each new element step-by-step. Consider the following retrospective voting model:

$$
\begin{aligned}
\text { Vote }_{i} & \sim \operatorname{Bernoulli}\left(\pi_{i}\right) & \text { Likelihood function } \\
\operatorname{logit}\left(\pi_{i}\right) & =\alpha+\beta\left(C_{0}-C_{t}\right) & \text { Linear model on } \pi_{i}
\end{aligned}
$$

Here, voters' object of retrospection is some abstract condition, $C$, which is thought to predict voter $i$ 's willingness to vote for the incumbent party, Vote $_{i}$. The dependent variable can take one of two values. Where voter $i$ said that they would vote for the incumbent party, it takes the value 1 . Otherwise, it takes the value 0 . The first step in building the model is to replace this abstract condition with a more meaningful one: change in the state of the economy. As I mentioned in the previous section, my measure of economic change is the percentage change in GDP between the most recent quarter of GDP data at the time of the election and all other quarters up to the last election. As the CSES are comparative and span many countries, there is also likely some country-specific variation to account for. To this end, I also include an adaptive prior on the intercept, $\alpha$, that allows it to vary from one country to the next:

$$
\begin{aligned}
& \text { Vote }_{i} \sim \operatorname{Bernoulli}\left(\pi_{i}\right) \\
& \operatorname{logit}\left(\pi_{i}\right)=\alpha_{\text {country }[i]}+\beta\left(\frac{G D P_{0}-G D P_{t}}{G D P_{t}} \times 100\right) \quad \text { Linear model on } \pi_{i} \\
& \alpha_{j} \sim \operatorname{Normal}\left(\bar{\alpha}, \sigma_{\alpha}\right) \text { for } j \text { in } 1 . . J \quad \text { Adaptive prior on varying intercepts } \\
& \bar{\alpha} \sim \operatorname{Normal}(0,1.5) \quad \text { Prior on grand mean of intercepts }
\end{aligned}
$$

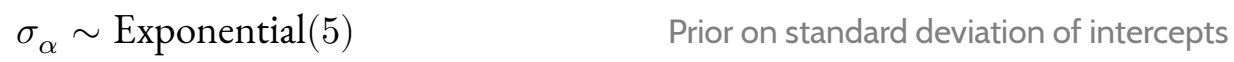


Note that the economic voting effect, $\beta$, is currently fixed for all values of $t$. Whether the present case concerns GDP change over the past quarter or, say, over the past 10 quarters, the estimate remains fixed. This makes little sense if voters are myopic. Instead, the economic voting effect should vary as a function of $t$. In particular, it should decay as $t$ increases to reflect the fact that people are more likely to forget events that took place a longer time ago.

One way to conceive of voter myopia is as a process of exponential decay ${ }^{4}$. In fact, an entire literature in psychology shows that human memory exhibits such a "forgetting curve" (see, for example, Murre and Dros 2015; Averell and Heathcote 2011). Where a quantity undergoes exponential decay, it begins at some initial value then diminishes quickly before levelling out as it approaches zero. As well as occuring in psychology, such processes are also common in the physical sciences. Consider, for example, the radioactive decay of a chemical element like plutonium or the amount of time a dosage of some drug will spend inside a person's body. I draw on these insights and model voter myopia using the following equation (Rösch 2014):

$$
N(t)=N_{0} e^{-\lambda t}
$$

In this equation, $N(t)$ represents the quantity of some substance $N$ at time $t$. When $t=0$, the equation simplifies such that $N(t)=N_{0}$, the substance's initial quantity. As time passes, the substance decays according to the value of its "decay constant," $\lambda$. The larger the decay constant, the faster the substance will decay. The amount of time that it takes for the substance to decay by half is known as its "half-life," $t_{1 / 2}$. Note that the decay constant, $\lambda$, and the half-life, $t_{1 / 2}$, also share a deterministic relationship. We can use this to our advantage, and use one value to compute the other:

$$
t_{1 / 2}=\frac{\log (2)}{\lambda}
$$

\footnotetext{
${ }^{4}$ This is similar to Hibbs' (1987) approach. Note, however, that unlike Hibbs, I do not fix the degree of exponential decay a-priori. Instead, I use my model to estimate it from the CSES and OECD data.
} 

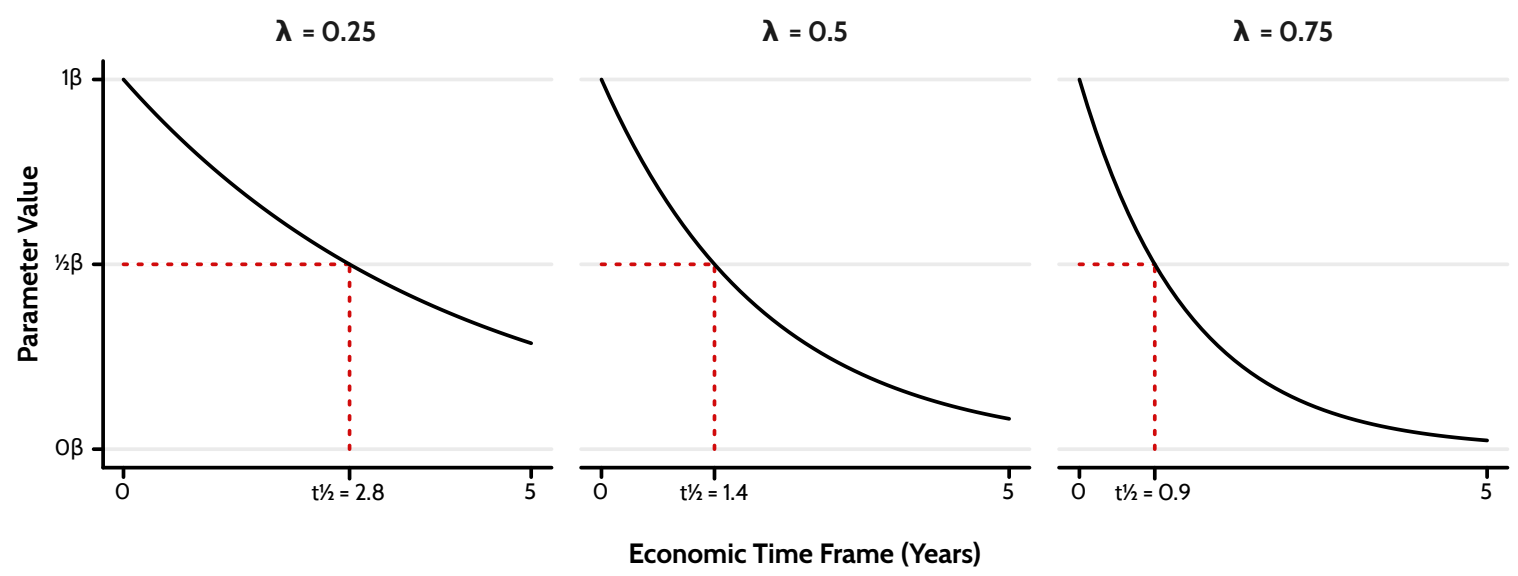

Figure 1: The decay constant and half-life are related. When the former increases, the latter decreases. This is because their relationship is deterministic. More specifically, $t 1 / 2=\log (2) / \lambda$.

Of course, in this case, the quantity of interest is not a substance. Instead, it is a parameter: the economic voting effect itself. Given this, we can substitute $N$ for the economic voting effect, $\beta$, to allow our model to estimate the economic vote while also permitting this effect to decay in size according to the time interval, $t$ :

$$
\beta_{t}=\beta_{0} e^{-\lambda t}
$$

It is worth pausing to consider how the decay constant and the half-life parameter are related in greater detail. Figure 1 shows how changes in the former affect changes in the latter. Moving from the left- to the right-most panel, the decay constant increases from 0.25 , to 0.5 , to 0.75 . As it does, two things occur. First, the economic voting effect decays more quickly. Second, the value of the half-life parameter, $t_{1 / 2}$, decreases to account for the increased rate of decay.

The simulation in figure 2 shows how this process might affect a voter's probability of voting for the incumbent across different time frames. In the left-most panel, the time interval between the election date and the reference date is zero. In effect, the voter evaluates the state of the economy in the immediate present. In this scenario, there is a strong economic voting effect: as GDP change increases, voters become more likely to vote for the incumbent party. This is true also in the centre-most and right-most panels, though, in both cases, the economic voting effect diminishes due to voter myopia. In the centre-most panel, where the time frame equals one year, 

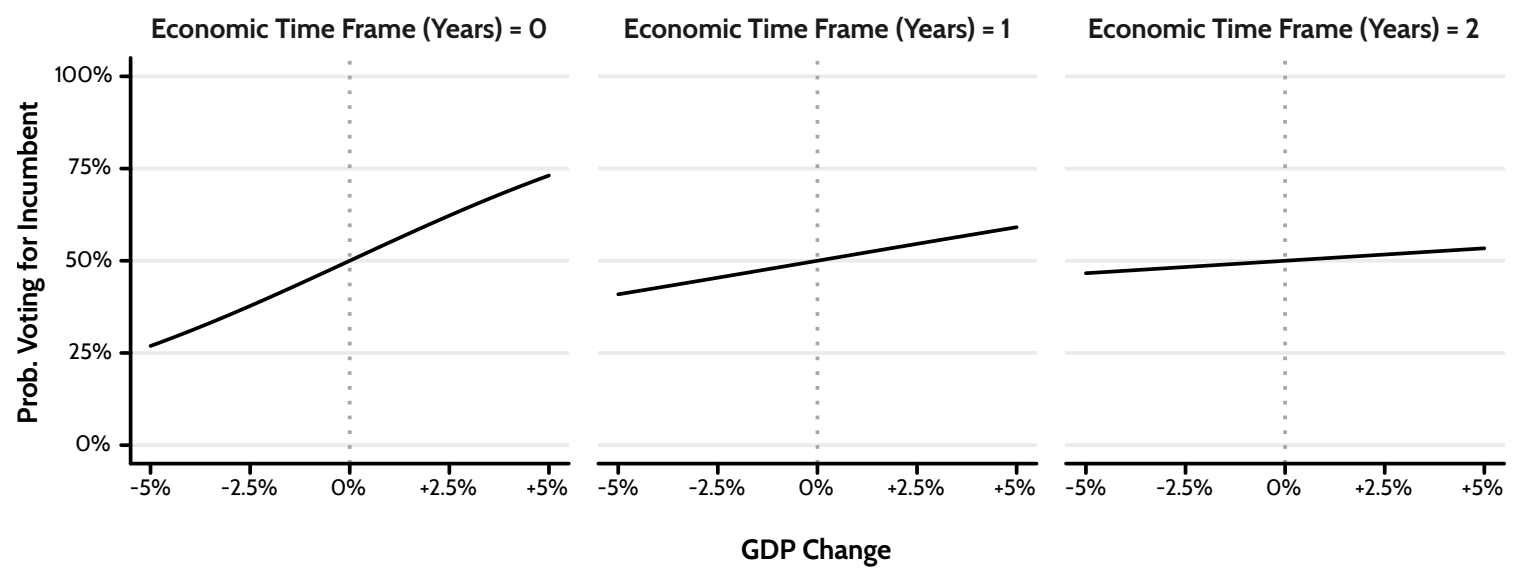

GDP Change

Figure 2: The slope is related to the time interval that voters use. As the interval increases, the slope decays. In this example, the slope at time $O$ is held at 0.2 and the decay constant is held at 1 .

some effect persists, though it is now more modest than when the time interval was zero. In the right-most panel, where the economic time frame equals two years, the economic vote has decayed to such an extent that it is hard to distinguish from zero.

The last step in the model-building process is to substitute the exponential decay model into the retrospective voting model, thereby giving my final model ${ }^{5}$ :

$$
\begin{array}{rlr}
\operatorname{Vote}_{i} & \sim \operatorname{Bernoulli}\left(\pi_{i}\right) & \\
\operatorname{logit}\left(\pi_{i}\right) & =\alpha_{\text {country }[i]}+\beta_{t}\left(\frac{G D P_{0}-G D P_{t}}{G D P_{t}} \times 100\right)+\delta \text { Years } & \text { Likelihood function } \\
\beta_{t} & =\beta_{0} e^{-\lambda t} & \text { Linear model on } \pi_{i} \\
\alpha_{j} & \sim \operatorname{Normal}\left(\bar{\alpha}, \sigma_{\alpha}\right) \text { for } j \text { in } 1 . . J & \text { Exponential decay model on } \beta_{t} \\
\bar{\alpha} & \sim \operatorname{Normal}(0,1.5) & \text { Adaptive prior on varying intercepts } \\
\sigma_{\alpha} & \sim \operatorname{Exponential}(2) & \text { Prior on grand mean of intercepts } \\
\beta_{0}, \delta, \lambda & \sim \operatorname{Normal}(0,0.5) & \text { Prior on standard deviation of intercepts }
\end{array}
$$

\footnotetext{
${ }^{5}$ Note that I also include a covariate to account for the passage of time, Years. This is important, as failing to account for secular changes that occur over time can confound one's estimates (Mellon and Prosser 2020; Woolridge 2012). Likewise, as this is a Bayesian model, I also include a prior distribution for each parameter. In all cases, I use conservative, non-informative priors that gently regularise my estimates towards zero.
} 
Table 1: Parameter estimates from the half-life model predicting incumbent voting intention. Data come from the Comparative Study of Electoral Systems' Integrated Module Dataset.

\begin{tabular}{lrrrr}
\hline & \multicolumn{4}{c}{ Half-Life Model } \\
& Estimate & Error & $2.5 \%$ & $97.5 \%$ \\
\hline Intercept, $\alpha$ & -0.59 & 0.07 & -0.73 & -0.45 \\
GDP $(\mathrm{t}=0), \beta_{0}$ & 0.04 & 0.01 & 0.03 & 0.05 \\
Decay Constant, $\lambda$ & 0.50 & 0.07 & 0.37 & 0.63 \\
Years Passed, $\delta$ & 0.14 & 0.01 & 0.12 & 0.16 \\
\hline $\mathrm{N}$ (Individuals) & & & & 151,822 \\
$\mathrm{~N}$ (Countries) & & & & 34 \\
LOOIC & & & & $203,050.0$ \\
WAIC & & & & $203,222.3$ \\
\hline
\end{tabular}

\section{Results}

Table 1 shows the resulting parameter estimates from my fitted model. In all cases, the model's parameters show relationships consistent with economic voting theory and voter myopia.

Contrary to the large effects often found in individual-level economic voting research, the economic voting effect that I identify is only small (0.04, 95\% CI: 0.03 to 0.05$)$. Note that this is not due to how I specify my model. As I show in my appendix, a conventional economic voting model comes to much the same conclusion (see table A1). Instead, the smaller effect size that I identify likely reflects two things. First, unlike subjective economic perception items, voters' own personal characteristics do not confound the effect that GDP data have on their willingness to vote for the incumbent party. Thus, there is little endogeneity to inflate them. Second, GDP change has a large range, so small effects can multiply to create much larger ones.

As past research on voter myopia would lead us to expect, the decay constant that controls voter myopia is positive $(0.50,95 \% \mathrm{CI}: 0.37$ to 0.63$)$. As I discuss above, there is a simple transformation that converts between this and the half-life parameter. Doing so reveals that the economic vote has a half-life of 1.40 years (95\% CI: 1.10 to 1.86 ), or about a year and a half . In simpler terms, this implies that the economic vote is half as strong when voters compare the

\footnotetext{
${ }^{6}$ I compute this figure by transforming the entire posterior distribution of the decay constant, $\lambda$, before taking its median and not simply transforming the point estimate shown in table 1 . As such, there may be a small discrepancy between the values that one arrives at using these two approaches.
} 


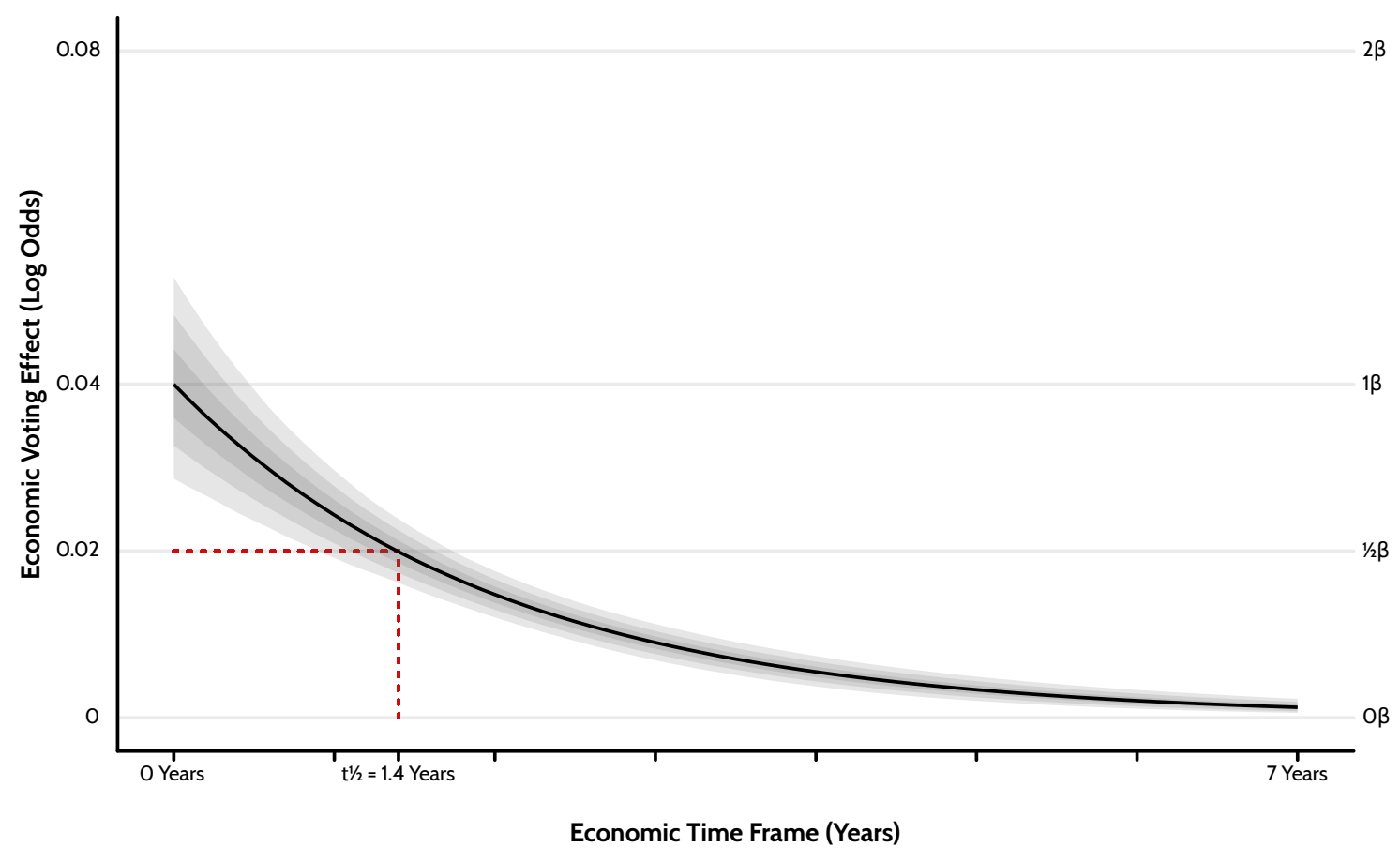

Figure 3: The economic vote diminishes as the time interval between the survey and reference date increases. At a time interval of 1.4 years, the economic voting effect decays to half of its initial value. Here light, medium, and dark areas reflect $95 \%, 80 \%$, and $50 \%$ credible intervals, respectively.

state of the economy now to the state of the economy 1.4 years ago than when they consider only the state of the economy right now.

It can be difficult to know how to interpret these parameters given that the model has so many moving parts. Accordingly, figure 3 shows how the economic voting effect decays as the economic time frame increases. Where the time frame is equal to zero, the economic voting effect is the same effect as shown in table 1 . As the time interval increases, the economic voting effect recedes, before it then diminishes to be practically-equivalent to zero at around seven years.

Note that as the economic voting effect diminishes, the uncertainty interval around its true value decreases. This might seem unusual: why should the model be more certain about the effect of GDP growth over seven years than, say, over one year or even over one month? To understand why, consider the nature of exponential decay. Any quantity that undergoes this process will decay to such a small value that it is, for all intents and purposes, equal to zero. This is an informative constraint: we know that the larger the time interval, the more certain we should be that the parameter equals zero. Thus, our uncertainty narrows as time goes on. 


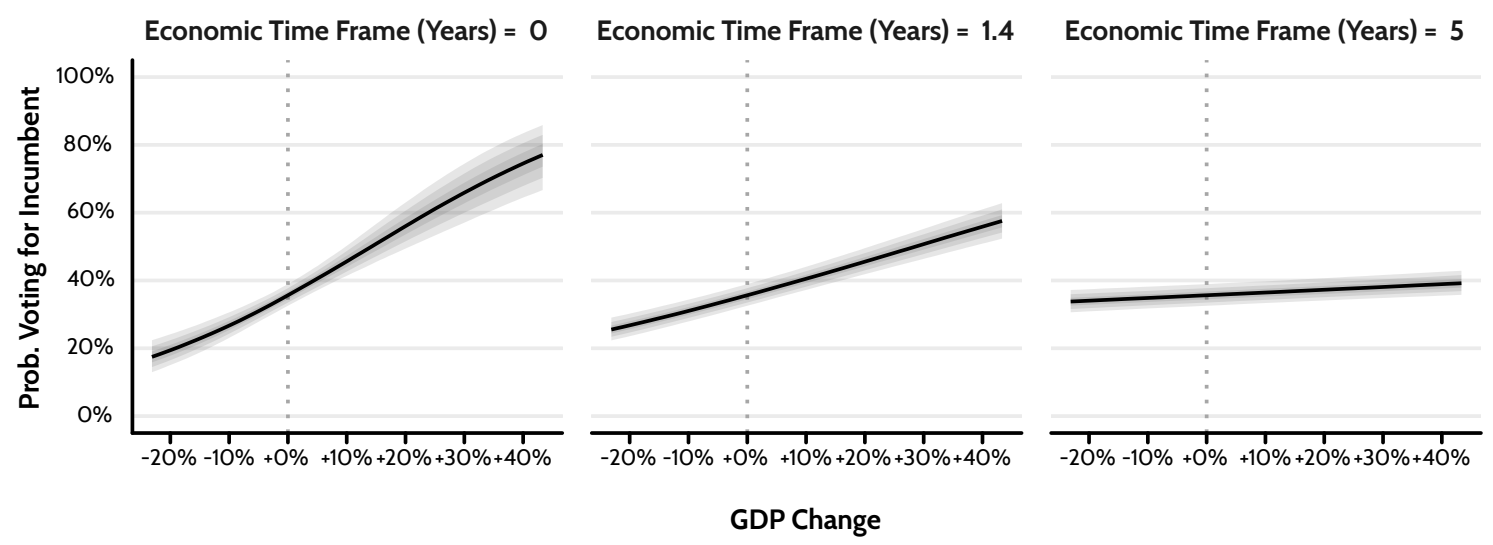

Figure 4: At $\mathrm{t}=\mathrm{O}$, the economic vote shifts the probability of voting for the incumbent a good deal. After 1.4 years have passed, this effect lessens. And after 5 years, it lessens even further. Again, light, medium, and dark areas reflect $95 \%, 80 \%$, and $50 \%$ credible intervals.

Figure 4 shows how economic myopia conditions voters' support for the incumbent party at three different time intervals. The left-most panel shows how the probability of supporting the incumbent changes where voters consider the state of the economy in the immediate present. The effect is reasonable in size, if uncertain: voters are a few percentage points more likely to support the incumbent where the economy is growing than where it is not. Their level of support then diminishes as their retrospective time frames increase in the centre- and right-most panels. Comparing the state of the economy now to what it was five years ago appears to have only a small effect on the probability of voting for the incumbent party ${ }^{7}$. Thus, it appears that voters really are myopic.

\section{Robustness Checks}

Sceptics might argue that, like Hibbs (1987), I have no good evidence that voters' memories undergo exponential decay. If some other functional form were better able to characterise the economy's waning influence on incumbent support, then my results might be incorrect. To be clear, I inform my choice of decay function using prior theory. As I mention above, there is an extensive and well-validated literature on the psychology of memory that finds that memories

\footnotetext{
${ }^{7}$ It is worth also noting that the economic time frame that voters use and the level of economic growth will often have a strong positive correlation. After all, economies almost always grow over time. Still, as the coronavirus pandemic has demonstrated, it is perfectly possible for a country to experience double-digit negative growth in only a very short period of time. That Irish GDP grew 26\% in a single year (OECD 2016; Halpin 2016) shows that the opposite case is also possible, if rare.
} 


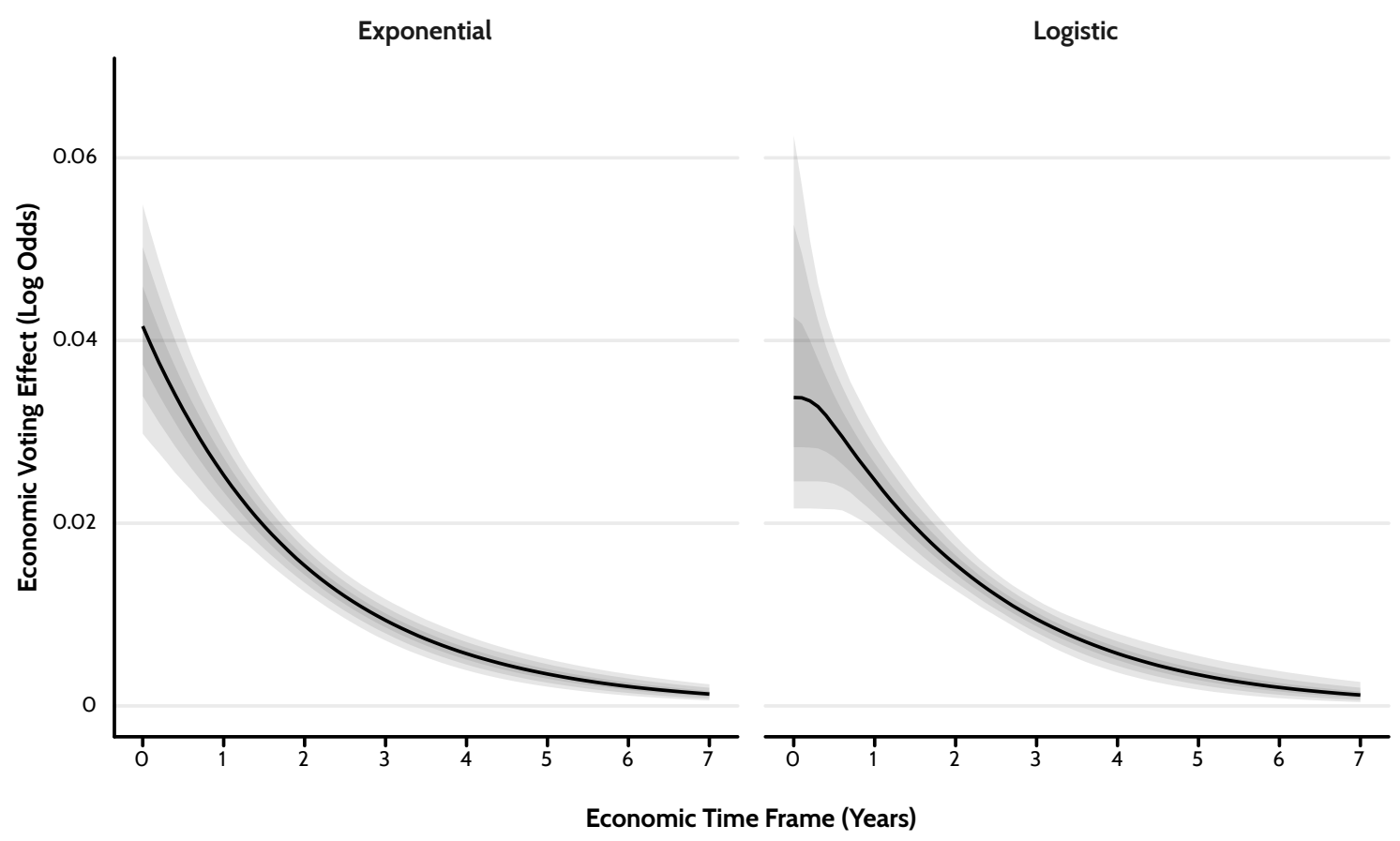

Figure 5: Assuming either an exponential or a logistic decay function results in almost exactly the same findings. The exponential function, however, shows a better fit to the data. Here light, medium, and dark areas reflect $95 \%, 80 \%$, and $50 \%$ credible intervals, respectively.

undergo a similar decay process (Murre and Dros 2015; Averell and Heathcote 2011). Further, the half-life equation that I borrow from the physical sciences serves only to provide a useful way of describing this process. That is to say, it does not require any assumptions beyond those of a typical exponential decay.

The only real challenger to the exponential decay function in the literature is the logistic decay function that Wlezien (2015) argues for. In practice, the two functions are very similar. Both start at some initial value, undergo a process of decay, then eventually approach zero. Their primary difference is that unlike the exponential function, the logistic function shows an initial plateau before any decay occurs. This would make sense if we expected voters to vote based on a broad consideration of economic change over, say, the past two years before the date of the election. Whether they do so is debatable and, again, requires that we estimate the necessary parameters from the data.

This presents us with two competing hypotheses. The first, that voter myopia undergoes a process of exponential decay. The second, that voter myopia undergoes a process of logistic decay instead. To test my model's robustness to this potential challenger, I refit my model assuming 
a logistic decay function instead (for the corresponding parameter estimates, see table A2). As figure 5 shows, the resulting logistic decay model (right-hand panel) implies voter myopia of almost exactly the same nature as the exponential decay model (left-hand panel). Yet the logistic model showed a worse fit to the data when compared based on a range of information criteria. For example, it had a higher LOOIC score $($ Logistic $=203,086.1$, Exponential $=203,050)$ and a higher WAIC score $($ Logistic $=203,202.1$, Exponential $=203,222.3)$. Comparing the two models based on their respective model weights (the probability that one model will show the best fit to the data compared to the other) corroborated this conclusion: the exponential model had a model weight of $99.91 \%$ and the logistic model of just $0.09 \%$. As such, my model appears to characterise voter myopia well, at least compared to its most prominent competitor.

\section{Conclusion}

Voter myopia is real. But, as Wlezien (2015) argues, this does not mean that they are as shortsighted as past research would suggest. My results show that voters do not have economic times frames that span only the election year (Healy and Lenz 2014) or even just the past few months (Achen and Bartels 2016). But neither do they imply that the past economy has some abiding effect on which party voters choose to support (Stiers, Dassonneville, and Lewis-Beck 2019). Rather, voters respond most strongly to economic change that has taken place over the past few years, but with diminishing effect.

In one respect, that voter myopia is less severe than we might have thought is reassuring. Put simply, it means that governments must contend with the consequences of more of their actions. Some suggest that this myopia might reflect a rational decision on the part of the electorate (Achen and Bartels 2016; Wlezien 2015): it makes sense to ignore the first view years of economic change if decisions that the incumbent's predecessor made continue to reverberate through the system. I am not so sure. Given that forgetting is a natural part of information processing I, like Huber, Hill, and Lenz (2012), suspect that this myopia arises due to fundamental limits on human cognition. Accordingly, I expect that it is simply a happy accident that voters remember more than we might have given them credit for in the past. 
Even so, that voters are myopic at all suggests that the two issues I raised in my introduction remain a problem. First, voters use economic time frames that are short enough to ensure that “myopic policies for myopic voters" (Tufte 1978, 143) remain a real concern. One way to combat this and to disincentivise government malfeasance might be to look to countries like Australia and New Zealand which have term lengths of only three years. After all, it is much easy to hold your government to account if you also have to evaluate less information when it comes time to vote. Second, as voters respond most strongly to recent economic change, strong economic manipulators might still outperform strong economic managers. To prevent this, we might begin to consider policies or campaigns that inform the public about the cumulative change that they say they consider most important in shaping how they vote (Healy and Lenz 2014).

Though these implications may be worrisome, long-term economic change could influence voters through other means. As Fieldhouse et al. (2020) argue, downturns can have lasting consequences beyond the direct effect that they have on jobs and living standards: they can affect how competent voters consider the incumbent party to be. Another possibility is that the small economic voting effects that I find here indicate only that voters respond to some other economic indicator. One obvious alternative is those topics made salient in the media that they consume (Garz and Martin 2020; B. B. Park 2019; Soroka, Stecula, and Wlezien 2015).

There are many opportunities to extend my analysis. One possible extension would be to engage with the literature on the apparent grievance asymmetry in economic voting (J. Y. Park 2019; Soroka 2006; Bloom and Price 1975). Given the serious ramifications that economic downturns have for voters' material well-being, it seems reasonable to expect their memories of bad times to outlast those of good ones. Allowing the decay constant, lambda, and the initial economic voting effect, $\beta_{0}$ to vary, say, pre- and post-crash would allow us to test for this. Finally, we might expect voters' economic time frames to differ according to their own personal characteristics. Though some voters do not pay attention to politics, some do. As such, more attentive voters might also be less myopic. Again, allowing the parameters to vary over these characteristics would allow one to test this hypothesis. In doing so, we might finally come to understand how voter myopia shapes democratic countries and the governments that they elect. 


\section{References}

Achen, Christopher H., and Larry M. Bartels. 2016. Democracy For Realists: Why Elections Do Not Produce Responsive Governments. Princeton, NJ: Princeton University Press.

Ansolabehere, Stephen, Marc Meredith, and Erik Snowberg. 2013. "Asking About Numbers: Why and How.” Political Analysis 21 (1): 48-69. https://doi.org/10.1093/pan/mps031.

Ariely, Dan, and Ziv Carmon. 2000. "Gestalt Characteristics of Experiences: The Defining Features of Summarized Events.” Journal of Behavioral Decision Making 13 (2): 11.

Averell, Lee, and Andrew Heathcote. 2011. "The Form of the Forgetting Curve and the Fate of Memories." Journal of Mathematical Psychology, Special issue on Hierarchical Bayesian Models, 55 (1): 25-35. https://doi.org/10.1016/j.jmp.2010.08.009.

Barabas, Jason, and Jennifer Jerit. 2010. “Are Survey Experiments Externally Valid?” American Political Science Review 104(2): 226-42. https://doi.org/10.1017/S0003055410000092.

Bloom, Howard S., and H. Douglas Price. 1975. "Voter Response to Short-Run Economic Conditions: The Asymmetric Effect of Prosperity and Recession.” The American Political Science Review 69 (4): 1240-54. https://doi.org/10.2307/1955284.

Campbell, Angus, Philip E. Converse, Warren E. Miller, and Donald E. Stokes. 1960. The American Voter. Chicago, IL: The University of Chicago Press.

Clarke, Harold D., Marianne C. Stewart, and Gary Zuk. 1986. "Politics, Economics and Party Popularity in Britain, 1979-83.” Electoral Studies 5 (2): 123-41. https://doi.org/10.1016/ 0261-3794(86)90002-8.

Conover, Pamela Johnston, Stanley Feldman, and Kathleen Knight. 1987. "The Personal and Political Underpinnings of Economic Forecasts.” American Journal of Political Science 31 (3): 559-83. https://doi.org/10.2307/2111283.

Coppedge, Michael, John Gerring, Carl Henrik Knutsen, Staffan I. Lindberg, Jan Teorell, David Altman, Michael Bernhard, et al. 2020. "V-Dem [CountryYear/CountryDate] Dataset V10.” Varieties of Democracy (V-Dem) Project.

Dunleavy, Patrick, and Hugh Ward. 1981. "Exogenous Voter Preferences and Parties with 
State Power: Some Internal Problems of Economic Theories of Party Competition.” British Journal of Political Science 11 (3): 351-80. https://doi.org/10.1017/S0007123400002684. Fieldhouse, Edward, Jane Green, Geoffrey Evans, Jonathan Mellon, Christopher Prosser, Hermann Schmitt, and Cees van der Eijk. 2020. Electoral Shocks: The Volatile Voter in a Turbulent World. New York, NY: Oxford University Press.

Fiorina, Morris P. 1981. Retrospective Voting in American National Elections. New Haven, CT: Yale University Press.

Garz, Marcel, and Gregory J. Martin. 2020. "Media Influence on Vote Choices: Unemployment News and Incumbents' Electoral Prospects.” American Journal of Political Science, July, ajps.12539. https://doi.org/10.1111/ajps.12539.

Goodhart, C. A. E., and R. J. Bhansali. 1970. "Political Economy." Political Studies 18 (1): 43-106. https://doi.org/10.1111/j.1467-9248.1970.tb00659.x.

Green, Donald, Bradley Palmquist, and Eric Schickler. 2002. Partisan Hearts and Minds: Political Parties and the Social Identities of Voters. Yale University Press.

Halpin, Padraic. 2016. "Irish 2015 GDP Growth Raised to 26 Percent on Asset Reclassification.” Reuters. https://uk.reuters.com/article/uk-ireland-economy-idUKKCNOZSOZC.

Healy, Andrew, and Gabriel S. Lenz. 2014. "Substituting the End for the Whole: Why Voters Respond Primarily to the Election-Year Economy.” American Journal of Political Science 58 (1): 31-47. https://doi.org/10.1111/ajps.12053.

Hibbs, Douglas A. 1987. The American Political Economy: Macroeconomics and Electoral Politics. Cambridge, MA: Harvard University Press.

- - - 2006. "Voting and the Macroeconomy." In The Oxford Handbook of Political Economy, edited by Barry R. Weingast and Donald Wittman, 565-86. Oxford, UK: Oxford University Press.

Huber, Gregory A., Seth J. Hill, and Gabriel S. Lenz. 2012. "Sources of Bias in Retrospective Decision Making: Experimental Evidence on Voters' Limitations in Controlling Incumbents." The American Political Science Review 106 (4): 720-41.

Kayser, Mark Andreas, and Christopher Wlezien. 2011. "Performance Pressure: Patterns of 
Partisanship and the Economic Vote.” European Journal of Political Research 50 (3): 36594. https://doi.org/10.1111/j.1475-6765.2010.01934.x.

Kiley, Kevin, and Stephen Vaisey. 2020. "Measuring Stability and Change in Personal Culture Using Panel Data.” American Sociological Review 85 (3): 477-506.

Kramer, Gerald H. 1971. "Short-Term Fluctuations in U.S. Voting Behavior, 1896-1964.” The American Political Science Review 65 (1): 131-43. https://doi.org/10.2307/1955049.

———. 1983. "The Ecological Fallacy Revisited: Aggregate- Versus Individual-Level Findings on Economics and Elections, and Sociotropic Voting." The American Political Science Review 77 (1): 92-111. https://doi.org/10.2307/1956013.

Lanoue, David J. 1987. "Economic Prosperity and Presidential Popularity: Sorting Out the Effects.” Western Political Quarterly 40 (2): 237-45. https://doi.org/10.1177/10659129 8704000203.

Lebo, Matthew J., and Daniel Cassino. 2007. “The Aggregated Consequences of Motivated Reasoning and the Dynamics of Partisan Presidential Approval.” Political Psychology 28 (6): 719-46. https://doi.org/10.1111/j.1467-9221.2007.00601.x.

Lebo, Matthew J., and H. D Clarke. 2000. "Modelling Memory and Volatility: Recent Advances in the Analysis of Political Time Series.” Electoral Studies 19 (1): 1-7. https://doi.org/10.1 016/S0261-3794(99)00039-6.

Lebo, Matthew J, Robert W Walker, and Harold D. Clarke. 2000. "You Must Remember This: Dealing with Long Memory in Political Analyses.” Electoral Studies 19 (1): 31-48. https: //doi.org/10.1016/S0261-3794(99)00034-7.

Lewis-Beck, Michael S., and Marina Costa Lobo. 2017. “The Economic Vote: Ordinary Vs. Extraordinary Times.” In The Sage Handbook of Electoral Behaviour, edited by Kai Arzheimer, Jocelyn Evans, and Michael S. Lewis-Beck, 2:606-30. Thousand Oaks, CA: Sage.

Lewis-Beck, Michael S., Richard Nadeau, and Martial Foucault. 2013. "The Compleat Economic Voter: New Theory and British Evidence.” British Journal of Political Science 43 (2): 241-61. https://doi.org/10.1017/S0007123412000440. 
MacKuen, Michael B., Robert S. Erikson, and James A. Stimson. 1992. "Peasants or Bankers? The American Electorate and the U.S. Economy.” The American Political Science Review 86 (3): 597-611. https://doi.org/10.2307/1964124.

Mellon, Jonathan, and Christopher Prosser. 2020. "Correlation with Time Explains the Relationship Between Survey Nonresponse and Mass Polarization.” The Journal of Politics 83 (1): 390-95. https://doi.org/10.1086/709433.

Murre, Jaap M. J., and Joeri Dros. 2015. "Replication and Analysis of Ebbinghaus' Forgetting Curve.” PLOS ONE 10 (7): e0120644. https://doi.org/10.1371/journal.pone.0120644.

OECD. 2016. "Irish GDP up by $26.3 \%$ in 2015 ?"

——-. 2021. “Quarterly National Accounts.” https://stats.oecd.org/Index.aspx?DataSetCode=QNA.

Paldam, Martin, and Peter Nannestad. 2000. "What Do Voters Know about the Economy?: A Study of Danish Data, 1990.” Electoral Studies 19 (2): 363-91. https://doi.org/10.1016/ S0261-3794(99)00057-8.

Palmer, Harvey D., and Guy D. Whitten. 2011. "Through Thick and Thin? The Dynamics of Government Support Across Income Groups During Economic Crises.” Electoral Studies, Special Symposium on the Politics of Economic Crisis, 30 (3): 427-37. https://doi.org/10 $.1016 /$ j.electstud.2010.11.008.

Park, Brandon Beomseob. 2019. "Compared to What? Media-Guided Reference Points and Relative Economic Voting.” Electoral Studies 62 (December): 102085. https://doi.org/10 $.1016 /$ j.electstud.2019.102085.

Park, Ju Yeon. 2019. "Punishing Without Rewards? A Comprehensive Examination of the Asymmetry in Economic Voting.” Electoral Studies 57 (February): 1-18. https://doi.org/ 10.1016/j.electstud.2018.10.003.

Quinlan, Stephen, Christian Schimpf, Katharina Blinzler, Slaven Zivkovic, and Bojan Todosijevic. 2018. “The Comparative Study of Electoral Systems (CSES) Integrated Module Dataset (IMD).”

Reidy, Theresa, Jane Suiter, and Michael Breen. 2017. “Boom and Bust: Economic Voting in Ireland.” Politics, 148-64. https://doi.org/10.1177/0263395716680827. 
Rösch, Frank. 2014. Nuclear and Radiochemistry, Volume 1: Introduction. Vol. 1. Berlin, DE: De Gruyter.

Soroka, Stuart N. 2006. "Good News and Bad News: Asymmetric Responses to Economic Information.” Journal of Politics 68 (2): 372-85. https://doi.org/10.1111/j.1468-2508.2 006.00413.x.

Soroka, Stuart N., Dominik A. Stecula, and Christopher Wlezien. 2015. "It's (Change in) the (Future) Economy, Stupid: Economic Indicators, the Media, and Public Opinion.” American Journal of Political Science 59 (2): 457-74. https://doi.org/10.1111/ajps.12145.

Stevenson, Randolph T., and Raymond Duch. 2013. "The Meaning and Use of Subjective Perceptions in Studies of Economic Voting.” Electoral Studies 32 (2): 305-20. https://doi. org/10.1016/j.electstud.2013.02.002.

Stewart, Marianne C., and Harold D. Clarke. 2017. "Economic Voting." In The Routledge Handbook of Elections, Voting Behavior and Public Opinion, edited by Justin Fisher, Edward Fieldhouse, Mark N. Franklin, Rachel Gibson, Marta Cantijoch, and Christopher Wlezien, 192-204. Abingdon: Routledge.

Stiers, Dieter, Ruth Dassonneville, and Michael S. Lewis-Beck. 2019. “The Abiding Voter: The Lengthy Horizon of Retrospective Evaluations.” European Journal of Political Research 59 (3): 646-68. https://doi.org/10.1111/1475-6765.12360.

Tufte, Edward R. 1978. Political Control of the Economy. Princeton, NJ: Princeton University Press.

Wlezien, Christopher. 2015. “The Myopic Voter? The Economy and US Presidential Elections.” Electoral Studies 39 (September): 195-204. https://doi.org/10.1016/j.electstu d.2015.03.010.

Woolridge, Jeffrey M. 2012. Introductory Econometrics: A Modern Approach. Fifth. Mason, OH: Cengage Learning.

Zaller, John R. 1992. The Nature and Origins of Mass Opinion. Cambridge, UK: Cambridge University Press. 
Table A1: Parameter estimates from my conventional economic voting model. Here, year-onyear GDP change data come from the OECD's Quarterly National Accounts individual-level voting intention data come from the Comparative Study of Electoral Systems' Integrated Module Dataset

\begin{tabular}{lrrrr}
\hline & \multicolumn{3}{c}{ Standard Year-on-Year Model } \\
& Estimate & Error & $2.5 \%$ & $97.5 \%$ \\
\hline Intercept, $\alpha$ & -0.59 & 0.08 & -0.75 & -0.45 \\
GDP (Year-on-Year), $\beta_{0}$ & 0.02 & 0.00 & 0.01 & 0.02 \\
Years Passed, $\delta$ & 0.16 & 0.01 & 0.14 & 0.18 \\
\hline N (Individuals) & & & & 151,822 \\
N (Countries) & & & & 34 \\
LOOIC & & & $211,646.2$ \\
WAIC & & & $235,399.2$ \\
\hline
\end{tabular}

Table A2: Parameter estimates from the logistic decay model predicting incumbent voting intention. Data come from the Comparative Study of Electoral Systems' Integrated Module Dataset.

\begin{tabular}{lrrrr}
\hline & \multicolumn{4}{c}{ Logistic Model } \\
& Estimate & Error & $2.5 \%$ & $97.5 \%$ \\
\hline Intercept, $\alpha$ & -0.60 & 0.07 & -0.75 & -0.47 \\
GDP $(\mathrm{t}=0), \beta_{0}$ & 0.04 & 0.01 & 0.02 & 0.06 \\
Decay Constant, $\lambda$ & 0.52 & 0.08 & 0.37 & 0.68 \\
Slope Concentration, $\phi$ & 0.96 & 0.86 & -1.25 & 2.04 \\
Years Passed, $\delta$ & 0.14 & 0.01 & 0.12 & 0.16 \\
\hline $\mathrm{N}$ (Individuals) & & & & 151,822 \\
$\mathrm{~N}$ (Countries) & & & & 34 \\
LOOIC & & & & $203,086.1$ \\
WAIC & & & & $203,202.1$ \\
\hline
\end{tabular}

